\title{
CHILDREN WITH DEFECTIVE VISION
}

BY

\author{
Prof. R. A. KAZ, M.D.
}

LENINGRAD

THE question of the education of children with defective vision is a problem of some standing. Where are such children to be taught ? In schools for the ordinary children with good average sight they see too badly and in schools for the blind they see two well. For, to try and teach the half-blind among the totally blind, the teachers of the blind say is pure punishment. They teach such a child to read with the fingers and the child always prefers to use such sight as he has. Instead of expelling children with defective sight from the schools for the blind these teachers of the blind consented to teach in the ordinary schools even quite blind children. Here is an inverse phenomenon: the college for the blind admits seeing children among its pupils. The explanation is that investigations of children in the college for the blind which were presented some years ago to to the Leningrad Society of Paedology revealed, contrary to all expectation, success in conservation of sight.

And so, the feebly-sighted children were transferred from the schools for the sighted to the college for the blind and from the college for the blind to the school for sighted children, and they find in neither place conditions suitable for their education.

What are these conditions?

For educational institutions as is said in my "Test-types for the determination of the sufficiency of the light reserve in schools and workshops" - not less than one-third of the normal vision is required, this is the degree of vision necessary for distinguishing the type corpus, where the height of the letter is $1.5 \mathrm{~mm}$. From the time of Cohn this type has been reputed as the least that is admissible in the schools. So then, the scholar ought to be completely satisfied for his teaching with vision of 0.33 . But in that case all remaining claims must be strictly accomplished: the lighting must have the due reserve, ${ }^{1}$ study must be conducted with frequent interruptions, the manuals must not be dirty, in the copy-books the lines must stand out quite clearly. Briefly it is necessary to keep in mind that the work is done by the eye at its maximal effort, without the sight-reserve of two-thirds by children with normal vision.

With vision of $0.2-0.1$ we have to employ larger types. In the A.B.C.-books there are such types. But it is impossible to sit continuously at A.B.C.-books. Here one will have to use a 
magnifying glass (telescopic spectacles) or to resort to reading on a magic lantern screen.

Finally, with vision of $0.05-0.02$ it is better to conserve this sight for daily life and to receive instruction among the blind-of course, if it is possible with physiotherapy to raise the vision this should be done. The case of the child F., aged eight years, where persistent physiotherapy succeeded in raising the vision from 0.03 to $0.7^{2}$ should be mentioned. Public officials should especially take note of this case, in the interest of sight-saving.

Nowadays the idea of sight-saving classes are world-wide. In America on this question are published two special journals: "The Sight-Saving Review" and "The Sight-Saving Class Exchange." Howard $^{3}$ reporting in St. Louis on a child with defective sight, pointed out that the cost of supporting these classes was about 2,000 dollars a year for a class ; and Weekers ${ }^{4}$ in his report, "The School for Semi-sighted," communicated to the Belgian Ophthalmological Society at the International Congress for Preventing of Blindness, on which representatives of France, England, America, Germany and Switzerland were occupied by questions of a school for children with defective vision; the design of the schools, the plan of teaching and preparation of a teacher for these schools. At last, classes for preservation of the sight of feebly-seeing children were commenced also in Leningrad, thanks to the endeavours of Drs. A. T. Pospielowa and N. G. Kratchkowskaja and of the teacher B. T. Kowalenko.

In the case of the child referred to, it is not only the teachers, whose duty it is to try and conserve vision as well as educate the child who must pay attention to this problem, but also all others whu attempt to raise the vision of the child to the possibility of his being taught in these classes, as well as such who allow themselves to think of the translation of feebly-seeing children into the common classes. But in these cases the request of Dr. Jackson, ${ }^{5}$ that such children "should be seen every few months" is insufficient.

One or two months before the school begins a daily or every other day course of physiotherapy will show if the vision of the little patients benefits or not by physiotherapy, one will know if it is suitable to let the children keep their places and also if it be possible or not to link to them a few others with still worse vision. Of course, such treatment is useless in the totally blind. But there are other cases which theoretically seem not to yield to any treatment, and in reality we are able to give these a sensible improvement in vision, thanks to physiotherapy. Such occurred in the abovenamed case, where the improvement of the vision was maintained till 0.7 passed into optic atrophy. Or, for example, myopia. At first sight it seems strange to think of visual amelioration in 
myopia. Indeed, the number of dioptres will not be changed the refractive anomaly itself will remain, but improvement of vision can occur in consequence of treatment of the retina in such a manner.

There is another case from my fore-cited article. ${ }^{2}$

S., aged 42 years. Myopia $19 \mathrm{D}$. with gross retinal changes. Vision of the right eye $=0 \cdot 1$, of the left $=0 \cdot 005$. After a treatment of three months R.V. $=0 \cdot 25, \mathrm{~L} . \mathrm{V} .=0 \cdot 15$.

In a year his nephew appeared. He was aged 21 years. Myopia $13 \mathrm{D}$. without obvious changes in the retina. The vision of both eyes was $=0 \cdot 2$. On the insistent request of the patient I gave him binocular physiotherapy for the retina. In three months' time he had steady vision of 0.5 in both eyes.

Thus, the children who show feeble vision which cannot be corrected by glasses are to be distributed in three groups. The first two groups-with vision of 0.3 and 0.1 -are designed for the sightsaving classes, and for physiotherapy in the first instance; the third group is composed of border-line cases where the question whether the children must go for teaching to the blind, or if they can be sent into the sight-saving classes must be solved. These two first groups can receive physiotherapic treatment without interrupting the study, if both institutions do not work simultaneously.

You may ask why it is necessary for children to have the ocular physiotherapy, when their sight is preserved by the sight-saving class? But, firstly, such a class is necessary, and as it has been stated the expenses are heavy. Secondly, even if a class exists for feebly-seeing children, it may happen that not every one is in a state to make use of such a class unless there has been previously an improvement of sight from physiotherapy. And thirdly, the removal from a common school, which becomes possible with the aid of physiotherapy, frees a place for a child more in need of preservation of sight, and to the freer of this place it gives something much greater for all his further life-the improvement of vision.

\section{REFERENCES}

1. Kaz, R.-Die Lichtvorratsorüfung in der Schulphotometrie. Internat. Arch. f. Schulhygiene, 1911.

2. Physiotherapy in incurable blindness. Russ. Ophthal. Jl., No. 3, 1931.

3. Howard.-Zentralbl. f. d. ges. Ophlhal. u. i. Grenz., Vol. XXIX, 1933.

4. Weekers.-Zentralbl. f. d. ges. Ophthal. u. i. Grenz., Vol. XXX, 1933.

5. Jackson, E.-School clinics. Amer. Jl. of Ophthal., No. 4, 1933. 